ulators - regardless of what decision was made regarding continued development of the molecule - would increase the safety of future studies. If this system were designed not to be so intrusive as to inhibit innovation but nonetheless to provide sufficient transparency, it would help to ensure that safety lessons need not be relearned repeatedly. Indeed, it is difficult to imagine how regulators can currently approve phase 1 studies without access to such data in a readily searchable format during the review process.

The details of this trial, including such crucial facts as the dose, rate of drug administration, planned number of doses, intervals between doses, and even whether multiple doses were received by any volunteer, were initially kept confidential under current laws in the United Kingdom. The MHRA has now decided to release the details of the trial, including its protocol, ${ }^{1}$ which makes clear that the intent was to study four groups of eight volunteers with each group receiving progressively higher doses; two volunteers in each group were to receive placebo. Only the first group was studied. However, this incident once again raises the question of whether such trials should be registered in an accessible database such as ClinicalTrials.gov. 5 There are fundamental questions about which, if any, details of a clinical trial involving volunteers should ever be confidential or whether safety and ethics principles can be ensured only by an open, transparent process in which such trials and protocols are registered in a public database. This issue has become more urgent in the light of both this recent incident and the migration of clinical trials to less developed countries, where oversight may be less rigorous.

Although it is important to emphasize that most phase 1 studies have been safe, it is equally important to ensure that lessons are learned from this experience and systems put in place to minimize the risk of recurrence. We must not squander the experience of the participants in such trials by failing to share the knowledge gained with their help. We have an opportunity to learn from events in the TeGenero study how to improve early drug evaluation, and we clearly need to do so as we develop more and more new compounds. Academia, the pharmaceutical and biotechnology industries, and regulators must work together to prevent such clinical-research nightmares from happening in the future.

An interview with Dr. Wood can be heard at www.nejm.org.

Dr. Wood is a professor of medicine and pharmacology at Vanderbilt University School of Medicine, Nashville. Dr. Darbyshire is the director of the Clinical Trials Unit of the Medical Research Council, London.

1. Press release of the Medicine and Healthcare Products Regulatory Agency. Latest findings on clinical trial suspension. April 5, 2006. (Accessed April 13, 2006, at http://www.mhra. gov.uk/home/idcplg?IdcService=SS_GET_ PAGE\&UseSecondary=true\&ssdocName= CON2023515\&ssTargetNodeld=389.)

2. North West London Hospitals press statements. (Accessed April 13, 2006, at http:// www.nwlh.nhs.uk/news/item.cfm?id=97.)

3. Stein CM. Managing risk in healthy subjects participating in clinical research. Clin Pharmacol Ther 2003;74:511-2.

4. Raper SE, Chirmule N, Lee FS, et al. Fatal systemic inflammatory response syndrome in an ornithine transcarbamylase deficient patient following adenoviral gene transfer. Mol Genet Metab 2003;80:148-58.

5. Drazen JM, Wood AJJ. Trial registration report card. N Engl J Med 2005;353:2809-11.

\title{
Compensation for Injured Research Subjects
}

\author{
Robert Steinbrook, M.D.
}

Wo recent developments increased awareness of the complications that may follow egg donation for stem-cell research and the disastrous consequences of a clinical trial of the humanized monoclonal antibody TGN1412 in which healthy volunteers nearly died (discussed above by Wood and
Darbyshire) - have focused renewed attention on the long-standing issue of compensation for injured research subjects. ${ }^{1}$ In the United States, despite decades of discussion and recommendations by national commissions, sponsors and institutions are not required to provide either free med- ical care or compensation, although some do. In contrast, many European countries mandate the provision of clinical-trials insurance, through which subjects are often covered regardless of fault.

Participation in clinical trials always carries some risk, but serious injury or death is rare, partic- 


\begin{tabular}{|ll|}
\hline $\begin{array}{l}\text { Characteristics of } 129 \text { Policies for Injuries to Research Volunteers at } 102 \text { Academic } \\
\text { Medical Centers in the United States.* }\end{array}$ & Policies \\
\hline Policy Provision & $n o .(\%)$ \\
\hline Free care not provided & $66(51.2)$ \\
\hline Medical treatment billed at usual and customary fees & 54 \\
$\begin{array}{l}\text { Emergency or immediate treatment billed at usual } \\
\text { and customary fees }\end{array}$ & 12 \\
Free care provided & $21(16.3)$ \\
Medical treatment & 10 \\
\hline Emergency or immediate care & 11 \\
Care billed to insurance first but free for those without insurance & $13(10.1)$ \\
Medical treatment & 9 \\
Emergency or immediate care & 4 \\
\hline Care billed on a case-by-case basis & $5(3.9)$ \\
No publicly accessible information & $24(18.6)$ \\
\hline
\end{tabular}

* Data are from a survey conducted by the Lewin Group ${ }^{4}$ and are primarily based on a review of sample informed-consent forms and other information from the Web sites of 126 major medical centers. Usable information was obtained from 102 institutions. The number of policies is greater than the number of institutions because some institutions had different policies for different circumstances, such as whether the research had a private sponsor.

ularly for healthy volunteers. There is, however, little systematic information about the severity, frequency, and types of injuries or about their costs. ${ }^{2}$ Injuries may result from the research procedure, as in the case of a spinal headache after a lumbar puncture, an ankle injury from falling off a treadmill, or the ovarian hyperstimulation syndrome after egg donation. Injuries may also result from the medication or device being tested or from an investigator's failure to follow the protocol or to perform the procedures correctly.

One view is that sponsors and institutions are obligated to compensate injured subjects, particularly in trials with commercial sponsors and regardless of who may be to blame or whether the participants were paid. ${ }^{2,3}$ The contrary view is that routine compensation is not required because subjects are made aware of the risks through the informed-consent process, understand them, and voluntarily agree to participate. There are also practical issues. For instance, it may be difficult to determine whether a medical problem is related to participation in a clinical trial, particularly if it develops months or years later or if a subject has other risk factors. The costs of providing compensation include the need to adjudicate claims and resolve disagreements. Plans with broad coverage are more costly and difficult to administer than those that are limited to covering direct medical costs.
As part of the informed-consent process for research "involving more than minimal risk," regulations of the Department of Health and Human Services require that potential subjects be told whether any compensation or medical treatments "are available if injury occurs and, if so, what they consist of, and where further information may be obtained." A recent study commissioned by the department found that most research institutions do not have policies that provide free care or compensation to injured participants (see table). ${ }^{4}$ The authors of the study reviewed 129 policies at 102 academic medical centers and found that there was "no institution or sponsor offering to compensate for lost wages or pain and suffering," that only 21 policies (16.3 percent) "involved providing free care or treatment," and that health insurance "serves as the primary vehicle for compensation of such injuries in the United States." ${ }^{4}$ The extent of coverage for research injuries may vary among health insurance policies.

The University of Washington is one institution with a longstanding compensation plan. The university's self-insured, no-fault plan dates from the 1970s. It covers medical expenses associated with adverse events and some incidental expenses, such as travel and child care. The division of financial responsibility between commercial sponsors and the university is specified in negotiated agreements. The university typically has one or two claims per year, and it writes off the cost of in-house medical expenses.

Institutional policies may not, 
of course, reflect what actually happens after an injury occurs or the role of litigation in helping subjects obtain compensation. ${ }^{5}$ Commercial sponsors may have their own policies regarding payments for treatment of injuries or contracts with institutions specifying who is responsible in various situations. Some institutions may require insurance arrangements. Some may absorb the costs of care for subjects who do not have health insurance or who have large copayments or deductibles. Some federal agencies - such as the Department of Veterans Affairs, the Department of Defense, and the National Institutes of Health Clinical Center - have requirements for the provision of short-term medical care to research subjects. The federal Medicare program will pay for care, including care for medical complications, for beneficiaries who take part in qualifying clinical trials.

The United States lacks national standards for either no-fault procedures or compensation guidelines for research-related injuries. The National Vaccine Injury Compensation Program, which has been in effect since 1988, is often cited as the closest example of such a standard. ${ }^{4}$ The program is a no-fault alternative to the traditional tort system for resolving vaccine injury claims. It covers all vaccines recommended by the Centers for Disease Control and Prevention for routine administration to children.

The situation in Europe is much different, in part because many countries have universal health insurance. The 2001 European directive on the conduct of clinical trials states that a trial may be undertaken only if "provision has been made for insurance or indemnity to cover the liability of the investigator and sponsor." Some countries - such as France, Germany, and Spain - have compulsory insurance laws, although there is variation in the specifics and in the minimum coverage that is required. ${ }^{2,4}$ Whereas clinical-trials insurance is not required in the United Kingdom, where the TGN1412 trial was conducted, government guidance for researchers - as well as the guidelines of the Association of the British Pharmaceutical Industry - states that compensation should be provided. Although such compensation may be adequate in many situations, it may be insufficient to cover extraordinary injuries, such as those in the TGN1412 trial.

In 2002, the Institute of Medicine issued the recommendation that "organizations conducting research should compensate any research participant who is injured as a direct result of participating in research, without regard to fault. Compensation should include at least the costs of medical care and rehabilitation, and accrediting bodies should include such compensation as a requirement of accreditation." ${ }^{2}$ Though little appears to have changed, there has been progress in the area of egg donation. In February 2006, the California Institute for Regenerative Medicine proposed regulations that would require institutions to which it pro- vides funding for deriving human stem-cell lines "to assume the cost of any medical care required as a direct and proximate result of oocyte donation for research." The institute has prohibited payment for a donor's time or eggs.

Although the ethical arguments for compensating injured research subjects are compelling, the practical details are complicated particularly the determination of the extent and duration of coverage and the assignment of the responsibility for paying compensation. However, the actuarial expense of covering direct medical costs may be relatively low, because serious injuries are unusual. In the United States, national leadership - from the clinicaltrials industry, academic medical centers, and the federal government - will be needed to catalyze major change.

$\overline{\text { Dr. Steinbrook (rsteinbrook@attglobal.net) }}$ is a national correspondent for the Journal.

1. President's Commission for the Study of Ethical Problems in Medicine and Biomedical and Behavioral Research. Compensating for research injuries: the ethical and legal implications of programs to redress injured subjects. Washington, D.C.: Government Printing Office, June 1982.

2. Institute of Medicine. Responsible research: a systems approach to protecting research participants. Washington, D.C.: National Academy Press, 2003.

3. Scott LD. Research-related injury: problems and solutions. J Law Med Ethics 2003;31: 419-28.

4. The Lewin Group. Task Order Proposal No. 2: care/compensation for injuries in clinical research. Draft of the final report prepared for the Department of Health and Human Services Office of the Assistant Secretary for Planning and Evaluation. Falls Church, Va.: The Lewin Group, May 18, 2005. (Contract no. HHS 100-03-0005.)

5. Mello MM, Studdert DM, Brennan TA. The rise of litigation in human subjects research. Ann Intern Med 2003;139:40-5. 
Reproduced with permission of the copyright owner. Further reproduction prohibited without permission. 